\title{
Espiritualidade e Ciências Sociais: um olhar do Serviço Social
}

Cristina Duarte ${ }^{1}$

\author{
Submetido em $\quad 11 / 12 / 2016$ \\ Aceite em 7/2/2017
}

Resumo: A reflexão em torno das Ciências Socias e a construção do pensamento em volta desta temática vem já de longe. Numa análise isolada, sem reduzir o social ao individual, verificamos que, se as Ciências Sociais estão ao serviço da condição humana, o mesmo acontece com o Serviço Social. Sedas Nunes refere que a realidade por elas estudada é uma só: a condição humana (Nunes 1987). Nesse sentido, as atividades humanas estão condicionadas ao facto de os homens viverem juntos (Arendt, 2009), num processo de interação e interdependência onde os aspetos históricos, sociais, antropológicos, psicológicos, físicos, espirituais podem congregar ou afastar os indivíduos. O Serviço Social bebe de diferentes saberes das Ciências Sociais e a sua atuação é com e no sujeito holístico. Nesse sentido, qual poderá ser hoje o contributo do Serviço Social no quadro das Ciências Sociais, partindo de um modelo de intervenção holístico, onde se atende a integralidade da pessoa, incluindo a espiritualidade?

Palavras-chave: Ciências Sociais, Espiritualidade, Holismo, Humanização, Serviço Social.

Abstract: The reflection around the Social Sciences and the construction of this theme has a long tradition. In an isolated analysis, without reducing the social to the individual, we find that, if Social Sciences are at the service of the human condition, the same happens with Social Work. Sedas Nunes states that the reality studied by them is one: the human condition (Nunes 1987). In this sense, human activities are conditioned by the fact that persons live together (Arendt, 2009), in a process of interaction and interdependence, where historical, social, anthropological, psychological, physical, and spiritual aspects can congregate or alienate individuals. The Social Work learns from different Social Sciences and acts on the subject in an holistic manner. In this sense, what can the contribution of Social Work be in the Social Sciences, starting from a model of holistic intervention, which serves the whole person, also as spiritual being?

Key-words: Social Sciences, Spirituality, Holism, Humanization, Social Work.

1 Doutoranda em Ciências Sociais, Especialidade Serviço Social com bolsa de investigação do Instituto Superior de Ciências Sociais e Políticas (ISCSP-UL); Mestrado em Serviço Social. Gestão de Unidades Sociais e Bem Estar pela Universidade Lusófona de Humanidades e Tecnologias (ULHT) e Docente nesta Universidade; Formação Avançada em Gestão de Organizações do Terceiro Sector pela Universidade Católica Portuguesa; Coordenadora do Grupo Espiritualidade e Ciências Sociais (GECS); Investigadora do Centro de Pesquisa e Estudos Sociais (CPES) da ULHT; Membro do Grupo de Investigação em Serviço Social (GISS) do ISCSP-UL; Membro do Conselho Consultivo da UDIP Colinas-SCML. Membro representante do ISCSP no Mind-Brain College of ULisboa. Especialista em Serviço Social, Assistente Social com quinze anos de prática interventiva. 


\section{Introdução}

A reflexão em torno das Ciências Sociais e a construção de pensamento em volta desta temática vem já de longe. Desde a sociologia à antropologia, história, passando pela psicologia, direito e filosofia, o que há de comum é o esforço por este conhecimento, sabendo que as fronteiras que possam isolar cada um destes saberes, são residuais. As múltiplas e complementares abordagens são hoje uma realidade, quer no plano da intervenção como da investigação, e é este um paradigma que podemos e devemos desenvolver.

É impossível criar um objeto de estudo em história sem conhecer os contextos culturais que condicionam comportamentos e estudar comportamentos sem concluir que estes são quem constroem as culturas. 0 exemplo espelha-nos, como não só há interligação das Ciências Sociais assim como estas são interdependentes.

$\mathrm{Na}$ complexidade dos sistemas e dos problemas da sociedade atual, há uma alternativa que é a criação de sinergias. Por isso, se as Ciências Sociais procuram conhecer a realidade da Humanidade em ordem a uma transformação, então, será o Serviço Social uma ciência porque empenhado nessa transformação?

Este questionamento e interligação é possível não só porque o Serviço Social está integrado nas Ciências Sociais, mas porque ligado a teorias sociais que apontam uma intervenção com tradição mais conservadora e uma cultura positivista, com Durkheim, Quelet e Le Play.

Passamos pelos fundamentos da Doutrina Social da Igreja, abrindo uma nova era de pensamento com a Encíclica do Papa Leão XIII Rerum Novarum, até a uma tradição mais dialética (ou revolucionária) personalizada no pensamento de Marx, Hegel e Engels. Assim, numa análise isolada, sem reduzir o social ao individual, verificamos que, se as Ciências Sociais estão ao serviço da condição humana, o mesmo acontece com o Serviço Social.

A integração do Serviço Social no campo das Ciências Sociais, e as Ciências Sociais como parte do corpo de saberes em Serviço Social, destaca ainda mais este cuidar da condição humana, da humanização do tecido social, a partir de diferentes culturas de pensamentos e ângulos de conhecimento, sabendo que a produção deste último é um processo de tensão entre diferentes paradigmas mas também de modelagem desses mesmos paradigmas à própria realidade social. Contudo, mais do que a uma realidade social, à pessoa, a cada pessoa. 
Entendemos que o sentido da condição humana engloba um cuidar de todas as dimensões da pessoa, incluindo a espiritual. Sabemos, porém, que há uma história ligada à génese das Ciências Sociais - já avançada e não terminada - sobretudo no que diz respeito à produção de conhecimento e à reflexão empírica, as quais o Serviço Social não acompanha, desde a sua génese. Sendo que a reflexão que se foca na dimensão espiritual do ser humano tende a ser investigada por áreas como a filosofia, teologia, e ciências das religiões, ciências da saúde, e menos nas ciências sociais e humanas, áreas como o Serviço Social e a Psicologia dão já passos nesse sentido, partindo da práxis profissional em contextos como os cuidados paliativos, tratamento das adições, entre outros.

O conceito de espiritualidade é entendido pela capacidade de transcendência, como parte do desenvolvimento pessoal num processo de auto-realização que passa não somente pela dimensão biológica, social, psíquica, mas também pela busca de profundidade e sentido de vida, da pessoa se entender e entender o mundo. Neste sentido, o texto explora o lugar da espiritualidade no quadro das Ciências Sociais, partindo do contexto do Serviço Social.

\section{O Serviço Social no quadro das Ciências Sociais}

Mas o que é então o Serviço Social? Uma profissão? Um conjunto de conhecimentos? Um serviço que se presta à sociedade? Uma ciência? Uma intervenção? Uma práxis que inclui uma teoria? Ou uma conjugação de saberes de diferentes ciências? Podemos afirmar que é a conjugação de tudo isto, sendo que, no processo de formação da profissão há um corpo de conhecimento adquirido, aprofundado e transmitido, mas nunca terminado. É certo que o quadro de conhecimento, sendo plural, pode também ele tender à dispersão, não permitindo entender, no imediato e no processo de formação académica, o âmago do Serviço Social.

Ou seja, o constructo de pensamento em Serviço Social é formado por uma pluralidade de saberes que se torna um desafio identificar a "ciência do Serviço Social", particularmente na área da investigação. E é por isso também que a interdependência e complementaridade do Serviço Social no quadro das Ciências Sociais é uma realidade em construção permanente, quer no campo da investigação como da intervenção e que deverão atender a toda e qualquer dimensão da pessoa.

No quadro das Ciências Sociais, enquanto instrumentos que procuram conhecer o mundo e as suas sociedades e transformações, Augusto Santos Silva afirmaria que 
um objetivo comum às Ciências Sociais é que todas procuram conhecer a realidade (Silva,1999, p.6). Para Gurvitch "o que caracteriza todas as Ciências do Homem é que a realidade por elas estudada é só uma: é a condição humana" (apud Nunes, 1987, p.21), pois o ser humano é um ser social, sendo que "todas as atividades humanas são condicionadas pelo facto de os homens viverem juntos” (Arendt, 2009, p.31).

No mapa das Ciências Socias, a área geográfica do Serviço Social não está delimitada a uma pequena parcela. O mapa traduz a realidade no seu todo e se, tendencialmente, procuramos estabelecer fronteiras, em rigor, os territórios são envolvidos pela dinâmica das relações entre pessoas e povos e pela "relação implícita com o processo de democratização das sociedades e com a construção de políticas públicas e uma relação explícita com os direitos humanos, a justiça social e a equidade" (Carvalho e Pinto, 2014, p. 3). O lugar do Serviço Social no mapa das Ciências Sociais, enquanto produtor de conhecimento, teve a sua afirmação pelas mãos de Mary Richmond com a sua obra Diagnóstico Social, já no séc. XIX, num esforço de se ter um entendimento objetivo da realidade, em vez de a intuir. Foi assim constituído o lugar, no campo do conhecimento científico. E podemos afirmar que o lugar é já o contributo. Ou seja, foi estabelecida, criada, uma "nova parcela" de terreno no campo das Ciências Sociais, "reconhecendo-se que ao nível da organização da profissão há uma conquista do espaço social” (Ferreira, 2013, p.41). Contudo, se o "lugar é o contributo", nem sempre o"lugar é um contributo" e, por isso, a nossa reflexão situa-se também no plano da avaliação desse lugar como terreno mais ativo ou mais passivo, mais improdutivo ou mais produtivo, no plano geral das Ciências Sociais, e numa dimensão que os profissionais das Ciências Sociais tocam no exercício de qualquer ação: a dimensão espiritual ${ }^{2}$.

Sendo o (a) assistente social um (a) profissional que toca e mergulha nos problemas sociais para, a partir do olhar de contextos reais, personalizados em histórias de vida, com nomes e rostos concretos, ao longo da história e nos diferentes contextos sociais, o Serviço Social olhou - e olha - a prática como uma prioridade, estando atento como sentinela, às desigualdades sociais e colaborando na coesão social. A preocupação do Serviço Social é estabelecer um laço entre as forças e as possibilidades internas do ser humano e as exigências exteriores, no interesse da

2 Segundo Machado (2008A), “porque é pessoa espiritual, o homem destaca-se e distingue-se dos outros seres vivos, nomeadamente dos animais. Aqui vai residir a sua unicidade como pessoa" (Machado, 2008, p.191) 
adaptação social do indivíduo ${ }^{3}$. A matéria-prima do Serviço Social é a pessoa e a pessoa nas suas diferentes dimensões “desenvolvendo-se em cinco contextos diferentes $^{4}$, os quais, apesar de poderem ser analisados separadamente, constituem parte de um todo" (ONU, 1999, p.24), e a pessoa em relação com a natureza e com outros homens. Uma adaptação que envolve toda a carga da histórica e da memória do individuo, as suas vivências, o sentido e o significado de vida que encontra e si e no mundo. E é por isso que, na afirmação de Berta Granja, “os assistentes sociais são constrangidos a uma adaptação permanente da atividade sociocognitiva que possibilita a ação profissional, devido a mudanças aceleradas: nos fenómenos sociais, nas relações sociais, nos problemas das populações; na multiplicação de conhecimento das ciências sociais e humanas que fundamentam a ação profissional..." (Granja, 2014, p.61). Mais escondido ou mais visível, o Serviço Social manteve e mantém o seu lugar na construção da história da humanização ${ }^{5} \mathrm{e}$ das Ciências Sociais (fig.1), hoje atento a uma intervenção que integre um modelo holístico, ou seja, atento a todas as dimensões da pessoa.

Figura 1 - Modelo interativo da construção do Serviço Social

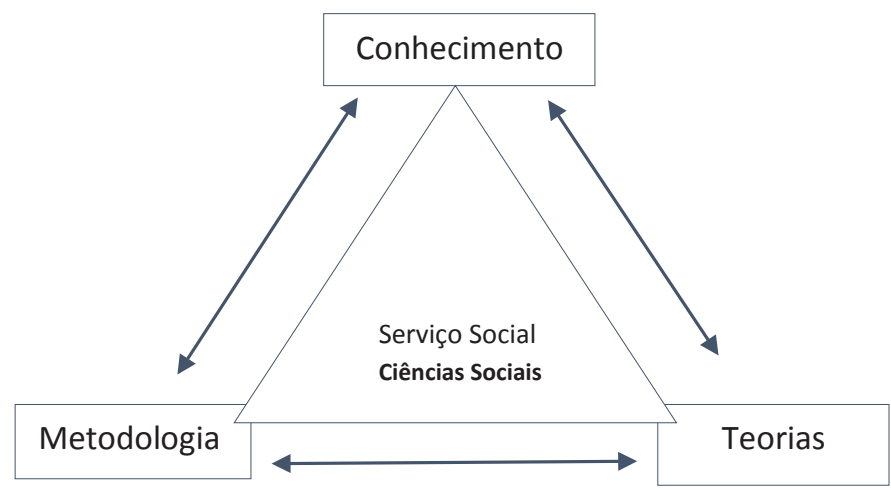

3 A intervenção em Serviço Social é uma intervenção humano-a-humano, ou seja, pessoa a pessoa. O Serviço Social é uma profissão da relação onde estão implícitas e (nem sempre) explicitas dimensões espirituais e emocionais, onde a "combinação de afeto, respeito pelo outro e vontade de agir compõe aquilo que me parece ser designado por "vocação", e que defendo claramente constituir uma condição essencial para o bom desempenho em qualquer área profissional, e, por maioria de razão, numa área que pressupõe relação e apoio” (Núncio, 2015, p.19).

4 Sendo que se podem analisar separadamente, esses contextos constituem parte de um todo. São eles o geográfico, o político, o sócio-económico, o cultural e o espiritual (cf. ONU, 1999, p.24)

5 A humanização em Serviço Social é entendida como a garantia e o cumprimento dos Direitos Humanos em cada pessoa, o reconhecimento da existência e da presença de um Outro, procurando colocar o ser humano no "centro da história". Está integrada num processo de humanismo, que inclui a integração de valores e ética na prática e na técnica, e que reintroduzem o ser humano no seu lugar relacional e solidário. A história do Serviço Social e dos seus fundadores está associada a esta constatação da fragilidade e vulnerabilidade humana, e ao compromisso de repor a pessoa no lugar da dignidade que lhe é devida, a partir de realidades e contextos onde o ambiente é sem alma e sem ternura (cf. Pessini, 2004), numa "relação implícita com o processo de democratização das sociedades e com a construção de políticas públicas e uma relação explícita com os direitos humanos” (Carvalho, 2014, p. 3). 
No quadro histórico do Serviço Social, encontramos o seu contributo de produção de conhecimento na década de 50, procurando a união entre a perspetiva médica, o conhecimento científico da doença e as necessidades do doente como pessoa. Foi no trabalho individual, case work, que o Serviço Social deu forma a um processo de intervenção e a um corpo teórico assente num modelo clínico da prática. São criados métodos em Serviço Social de Grupo e Serviço Social de Comunidade. Entram em ação os três motores da construção da profissão e o Serviço Social aparece como um processo dinâmico de estruturação, de desenvolvimento humano e social, assente numa base mais estável e mais exata. A reconceptualização do Serviço Social trouxe uma nova abordagem e compreensão pela interpretação fenomenológica do estudo científico em Serviço Social.

Em paralelo, e no campo da intervenção, reafirma-se a profissão pelo reconhecimento, colocando-a como exigência na formação das equipas que integram algumas respostas sociais, concretiza-se a integração em equipas multidisciplinares no campo da saúde, da educação, da proteção, dos serviços públicos. Porém, esta especificidade, não raras vezes, é posta em causa, porque o "ser específico" do Serviço Social não é fácil de delimitar, e por o Serviço Social assumir funções do plano da gestão e da administração. Por isso, o Serviço Social vai-se afirmando pelo desempenho técnico, numa capacidade para atuar através de técnicas específicas, usando métodos científicos que produzem conhecimento. O Serviço Social trabalha em instituições, de carácter público ou privado, e numa transversalidade de populações e problemáticas. São essas, e nessas instituições, que o Serviço Social revê a sua história e constrói história, e assim implementa e usa técnicas específicas no trabalho com as populações.

No plano político, o Serviço Social começa a ser chamado para a construção e discussão de políticas sociais na promoção de uma sociedade igualitária entre cidadãos. A afirmação do Serviço Social passa de uma profissão residualista para a mudança de situações que é chamado a produzir. Esta mudança, nos últimos anos, tem maior expressão em trabalhos científicos, o que levou o Serviço Social a integrar num saber-fazer e num saber-ser, um saber-saber. Internamente, o Serviço Social empenhou-se na criação de um Código Ético e Deontológico, legitimando os seus fundamentos filosóficos e definindo princípios e valores onde o profissional sustenta a sua prática. Atualmente a profissão está organizada e presente nos cinco continentes. O Serviço Social é hoje representado em Ordens, Associações, Conselhos e uma organização internacional - Internacional Federation of Social 
Workers - IFSW. Em paralelo, o Serviço Social tem vindo a afirmar-se noutras áreas de saber como a espiritualidade, a inteligência emocional, com alguma expressão, de modo particular no Canadá, Inglaterra e Estados Unidos da América, retomando assim uma das suas áreas de intervenção e assumindo uma ação holística.

o Serviço Social iniciou um processo de metamorfose, que o tem levado a passar de "consumidor" para um "produtor", também no campo das Ciências Sociais, com a tomada de consciência da necessidade de produção de conhecimento para legitimar a profissão. Nas palavras de Mouro, "ao seguir a via da reabilitação e da reinvenção, o Serviço Social cria o contexto necessário para a reprofissionalização na contemporaneidade" (Mouro, 2014, p.41). Este compromisso é agora mais visível na nova proposta da definição de Serviço Social, apresentada em Abril de 2013:

\begin{abstract}
"The social work professions facilitates social changes and development, social cohesion, and the empowerment and liberation of people. Principles of social justice, human rights, collective responsibility and respect for diversities are central for social work. Underpinned by theories of social work, social sciences, humanities and indigenous knowledge's, social work engages people and structures top address life challenges and enhance wellbeing" (European Association of Schools of Social Work and International Federation of Social Work, 2013).
\end{abstract}

No contexto apresentado, cabe-nos acrescentar que a par de uma afirmação ou rehabilitação da profissão há um contributo particular que advém do campo de intervenção do Serviço Social, e que este traz para o espaço das Ciências Sociais, enquanto agentes transformadoras da realidade social. No quadro das Ciências Sociais e da sociedade atual, que pode o Serviço Social trazer de transformador ao mundo? Acreditamos que as mudanças sociais trarão consequências transformadores positivas para o ser humano quando estas mudanças trouxerem o Homem para mais perto da sua essência, para mais perto de si, num processo onde o Serviço Social é um agente ativo, num mundo “, onde o mercado global do eu-mercadoria é um nó numa rede de mercados e dos sistemas de rating. Parece não existir qualquer profundidade histórica e cultural, nenhuma ancoragem interior do eu" (Strenger, 2011. p.41). E é nesta ancoragem e coesão social que o Serviço Social, a par de todas as Ciências Sociais, é convocado a agir de forma integrada e integradora. 


\section{Temas emergentes de investigação em Ciências Socias: Espiritualidade e Serviço Social}

Vivemos num mundo em constante mutação resultante dos processos de globalização, que inclui tecnologias de informação e da comunicação e a mudança de princípios e valores, onde "tudo o que espontaneamente adentra o mundo humano, ou para ele é trazido pelo esforço humano, torna-se parte da condição humana. 0 impacto da realidade do mundo sobre a existência humana é sentido e recebido como força condicionante" (Arendt, 2009, p.17).

A globalização "compreende uma perceção holística', que relativiza as referências nacionais e individuais perante a dimensão supranacional” (Ferreira, 2013, p.43). Este tipo de sociedade, simultaneamente global e local, produz oportunidades para os que vivem globalmente, mas produz também exclusão, sobretudo localmente. Uma sociedade com esta tipologia traz mais desafios aos profissionais, onde incluímos o Serviço Social, pois aumentam as desigualdades e a intervenção é cada vez mais racionalizada, incluindo o escrutínio dos assistentes sociais pelas entidades empregadoras. Desafios estes que face à própria fragilidade do Estado coloca em causa os valores fundacionais do Serviço Social e a ação dos profissionais. É neste cenário complexo, urgente e emergente, que o assistente social é chamado a uma intervenção efetiva, eficiente e eficaz, onde é chamado a "defender a pessoa como ser humano total" (Granja, 2015, p.73).

0 interesse económico sobrepõe-se aos interesses espirituais e relacionais, e é neste contexto de mudança de paradigma que o profissional vê muitos dos valores pelos quais se rege são traduzidos em ações que apenas satisfazem as necessidades primárias dos utentes, sem levar à uma verdadeira cidadania ativa que gere empowerment. Neste contexto, o profissional de Serviço Social é desafiado a desenvolver uma ação critica-operativa da intervenção sob o enquadramento dos direitos humanos e do humanismo (Payne, 2011), onde integre a espiritualidade ${ }^{7}$

6 A palavra holismo vem do grego holos que significa totalidade. A intervenção do Serviço Social dá-se pela via da dimensão social, psicológica, relacional, espiritual de cada pessoa, conhecendo a interdependência de cada uma destas dimensões.

7 A espiritualidade entende-se como uma dimensão de busca de significado e sentido para a vida, para além do tangível. É um processo de desenvolvimento na vida humana, acompanhando toda a vida nos diferentes aspetos da pessoa. Canda coloca a espiritualidade no centro da pessoa, atravessando todas as suas dimensões e abrangendo a totalidade da pessoa (Canda,2009). Entre as escalas usadas para avaliar a dimensão da espiritualidade, temos, por exemplo a Functional Assessment of Chronic ILLness Therapy - Spiritual Well -Being (FACIT -Sp -12) de Peterman, desenvolvida para doentes oncológicos em fase terminal, e que integra itens agrupados em duas dimensões: 0 sentido de vida e a paz/fé. 
$\mathrm{Na}$ história da metodologia e das teorias de intervenção e da relação de ajuda do Serviço Social, a sua preocupação nas metodologias era o "como fazer", e não tanto com o "porque fazer". o case work tornou a profissão mais personalizada e humanizada, assemelhando-o, como referimos, ao diagnóstico clínico da medicina, o que pressupõe uma atenção, uma escuta ativa, saber dissecar a panóplia de problemas e trazer a pessoa, tanto quanto possível, para o centro das decisões sobre a situação na qual é a primeira interessada.

Carl Rogers na sua metodologia de abordagem centrada na pessoa, reforça isto ao dizer que "a política de uma abordagem centrada na paciente implica que a terapeuta renuncie constantemente e evite controlar ou tomar decisões pela paciente. É proporcional à paciente uma autonomia de posse e é a estratégia pela qual isto pode ser conseguido; a determinação do centro da decisão e a responsabilidade pelos efeitos de tais decisões" (Rogers, 2011, p.27).

0 que acontece no processo de relação de ajuda é o desenvolvimento humano, onde, por princípio, há uma extensão de valores reciprocamente entregues, porque é na interação com os outros que também somos transformados no nosso processo de desenvolvimento. As teorias de intervenção do Serviço Social e o carácter social modificador que caracteriza a identidade da profissão fazem com que os profissionais, no programa de formação, tenham um número de disciplinas que são características das relações humanas, da busca pela dignidade da pessoa e, por isso, fundamentais no processo de relação de ajuda da intervenção, cuja finalidade é a mudança social que pode ocorre de forma súbita e/ou urgente (Cristina de Robertis, 2005).

O Serviço Social inspira-se nas Ciências Sociais e nas Ciências Comportamentais e, apesar da diferença da terminologia, o professor, o psiquiatra, o sociólogo, o antropólogo, utiliza, tal como o assistente social, bases de registo e sistemas de método semelhantes.

A filosofia do Serviço Social é ela própria democrática, e a sua ética não difere das de outras profissões, quando falamos da metodologia de relação de ajuda, que implica um olhar totalizante para a pessoa, que requer uma reciprocidade de laços, de compromisso, quer da parte da parte de quem ajuda como de quem é ajudado, pois "um individuo facilitador pode ajudar a libertar estas capacidades desde que se relacione com o "outro" como pessoa real; possuindo e exprimindo sentimentos próprios; experimentando pelo outro um interesse não possessivo e 
amor; compreendendo e aceitando o mundo interior dele" (Rogers, 2011, p.28). E é por é por aqui que definimos a intervenção com sentido espiritual.

Quando pensamos a sustentabilidade da profissão e o seu lugar e contributo no quadro das Ciências Sociais, o nosso olhar orienta-se para os contextos em que se desenvolve o Serviço Social. Dos cinco inumerados "geográfico, político, sócio-económico, cultural e espiritual" (Manual para Escolas e Profissionais de Serviço Social, 1999, p.24), a dimensão espiritual é de "importância central" (ibidem) pois é por ela que o assistente social afirma e confirma os valores pelos quais se orienta a profissão e a práxis (ibidem).Para Raúl Marino, "durante muitos anos a ciência tem negado a existência da gnose do espírito ou de qualquer tipo de inteligência que transcenda o domínio material, mostrando-nos os factos unicamente pelos sentidos (olhos da carne). Isso não quer dizer que a espiritualidade comece onde a ciência termina, pois ambas concorrem para a busca do real" (Marino, 2005, p.10).

0 contributo do transpessoa ${ }^{8}$ para o Serviço Social tem sido o da busca de sentido sobre a espiritualidade e a forma de expressá-la no trabalho profissional. 0 tema da espiritualidade, no contexto cultural português, assume não raras vezes, contornos religiosos ${ }^{9}$ associados a uma cultura de tradição cristã e, nesta, com expressão maioritariamente cristã católica. É fundamental aclarar o sentido da espiritualidade que tem como qualidade a transcendência, entendida como "aquilo que nos leva mais além - mais além do momento presente, da nossa alegria presente ou do nosso sofrimento, mais além dos nossos eus presentes. Leva-nos mais além do nosso conhecimento e experiência e coloca-os num contexto mais amplo " (Zohar e Marshall, 2004, p.84).

A espiritualidade no ser humano nasce e cresce da necessidade de se transcender, que é, em todos os tempos, a procura de respostas aos grandes dilemas da vida humana, a busca do sentido da vida: De onde venho? Para onde vou? Quem sou? Esta necessidade de se transcender é parte de um desenvolvimento pessoal num processo de auto-realização que passa não somente pela dimensão biológica, social, psíquica, mas também pela busca de profundidade para a pessoa se entender e entender o mundo. A espiritualidade pode estar interligada a manifestação da expressão religiosa, a experiências do sagrado, mas não é condição uma dimensão religiosa para a vivência da espiritualidade. A espiritualidade gera um movimento

8 A Psicologia Transpessoal, com as teorias de Carl Jung, Abraham Maslow, Viktor Frankl, referem que o ser humano transcende a sua psique (mente, consciente) para se poder unir a um todo ou a realidades mais abrangentes. Isto poderia ser possível pela prática da meditação, técnicas de relaxamento ou mesmo pela hipnose.

9 Para Rego et al. (2007), "a espiritualidade não requer, necessariamente, a conexão com qualquer tradição religiosa" (cf. Rego, et al., 2007, p. 10). 
de coerência, bem-estar e autoestima. A espiritualidade é uma qualidade inata de todas as pessoas que se manifesta de variadíssimas formas consoante as culturas, por isso se considera que todas as pessoas são espirituais, independente do lugar que o espiritual tenha na vida de cada pessoa. Motivar as pessoas e as comunidades para o desenvolvimento da espiritualidade saudável, poderá potenciar nestas a necessidade de busca de sentido, propósito, integridade pessoal, totalidade, plenitude, alegria, serenidade, felicidade, visão coerente e pleno bem-estar e transversal a todas as áreas da pessoa (fig. 2).

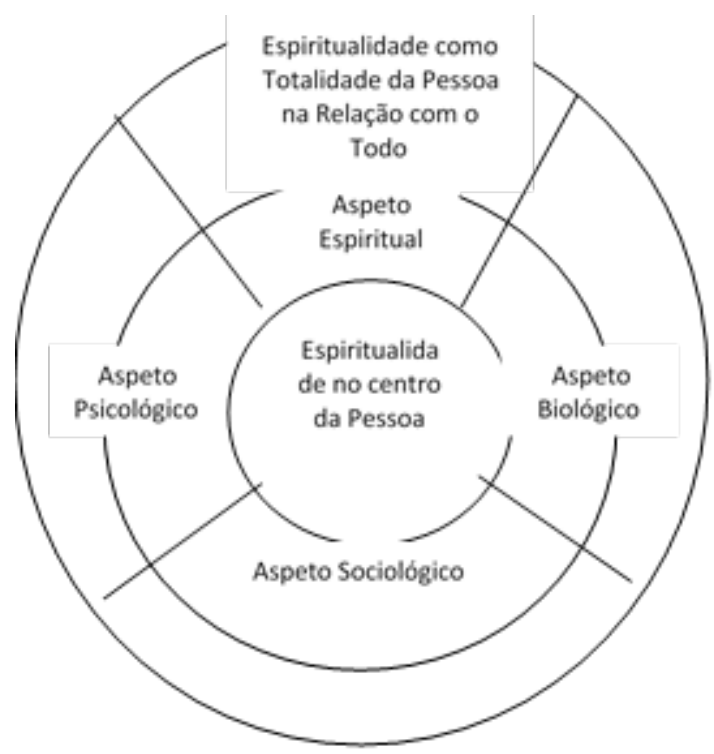

Figura 2 - Modelo de Edward Canda: o círculo interior é o centro da pessoa, o centro médio está dividido em quadrantes (os aspetos biológico, psicológico, sociológico e espiritual) e o círculo externo é a totalidade da pessoa na relação com o todo. Neste modelo, existem três metáforas de espiritualidade. No círculo médio, refere-se ao aspeto espiritual da pessoa, que complementa os outros três aspetos. Envolve a busca de um sentido e de relações morais satisfatórias consigo (self), outros e uma realidade suprema, porém é a pessoa que define isso. 0 círculo exterior representa espiritualidade como totalidade da pessoa na relação com o todo. Transcende e abraça os quatro aspetos da pessoa (Canda, 2009).

Assim, entendemos que a espiritualidade não é só parte do Homem mas parte das Ciêncais Sociais, na medida em que estas têm como objeto de estudo e intervenção - a sua matéria prima - o ser humano. A espiritualidade, e no possível lugar de investigação que se the possa dar no plano das Ciências Sociais, propõe uma 
meta de realização pessoal que converge com a realização pessoal dos outros, pois o ser humano só se cumpre na relação com outros.

E o que fazem as Ciências Sociais senão este estudo e empenho por devolver o Homem ao Homem, ou seja, à sua Humanidade mais profunda? Para Dalai Lama, a "espiritualidade diz respeito ao cuidado a ter com o espírito humano, como o amor e a compaixão, a paciência, a tolerância, o perdão, o contentamento, o sentido de responsabilidade e de harmonia, que trazem felicidade para si e os outros...as características comuns a todas as qualidades que descrevi como "espirituais" é o interesse pelo bem-estar comum" (Dalai Lama, 2000, p.21). E este deverá ser o principio e a finalidade que rege o trabalho dos interventores sociais.

\section{Considerações finais}

O Serviço Social é hoje, como nunca, chamado a participar na reconstrução social e a reposicionar-se no campo das Ciências Sociais através de um compromisso efetivo no espaço da teoria, da intervenção e da investigação. Para isso, torna-se necessário "olheiros" que detetam oportunidades de inovação. Manter o lugar e a contribuição no quadro das Ciências Sociais, exige redefinição do papel do assistente social no espaço público e privado e uma renovação de competências que tornem o profissional singular, na pluralidade, "sentindo-se compelidos a defender uma nova ordem mundial, que torne realidade o respeito pelos direitos humanos e dignidade, bem como uma estrutura diferente de relações humanas" (Global Agenda, 2012, p.1), envolvidas numa dimensão espiritual, porque holística. A afirmação dos Direitos Humanos não se dá somente pela via da assinatura de acordos, mas pela via da humanização personalizada, situada num contexto histórico, social, cultural, geográfico. Para isso, é urgente o trabalho integrador dos diferentes profissionais das Ciências Sociais. E a mudança social desejada e necessária, poderá começar por esta inclusão e cooperação de diferentes áreas que convergem num único sentido: a pessoa. 


\section{Bibliografia}

Arendt, Hannah (2007). A Condição Humana (10ª ed.). Rio de Janeiro: Forense Universitária.

Carvalho, Maria Irene; Pinto, Carla (2014). Serviço Social, teorias e práticas. Lisboa: Pactor,Edições das Ciências Sociais, Forenses e da Educação.

Canda, Edward (2009). Sensibilidade Espiritual no Serviço Social: uma revisão das tendências Norte Americanas e Internacionais", apresentação proferida na Conferência em Serviço Social e Counseling, Universidade de Hong Kong, China.

Ferreira, Aida (2013). Serviço Social e Desemprego de longa duração. Lisboa: Cáritas Portuguesa.

Granja, Berta (2014). Contributos para a Análise das Formas Identitárias dos Assistentes Sociais. In Carvalho, Maria Irene; Pinto, Carla (Coord), Serviço Social, Teorias e Práticas (pp. 57-81). Lisboa: Pactor.

Global Agenda for Social Work and Social Development (2012), IASSW, ICSW, IFSW.

Machado, António Gomes (2008). Edith Stein Pedagoga e Mística. Braga: Ed.AO.

Marino, Raúl (2005). A religião do cérebro, as novas descobertas da neurociência a respeito da fé humana (7 $7^{\mathrm{a}}$ ed.). São Paulo: Editora Gente.

Mouro, Helena (2014). Teoria e teorizar em Serviço Social. In Carvalho, Maria Irene; Pinto, Carla (Coord), Serviço Social, Teorias e Práticas (pp.27-56). Lisboa: Pactor.

Núncio, Maria José da Silva (2015). Introdução ao Serviço Social, História, Teoria e Métodos. $2^{a}$ edição, Lisboa: Instituto Superior de Ciências Sociais e Políticas.

Nunes, A. Sedas (1987). Questões preliminares sobre as Ciências Sociais: Lisboa, Ed. Presença,pp.21-73.

Organização das Nações Unidas (1999). Direitos Humanos e Serviço Social - Manual para Escolas e Profissionais de Serviço Social: Lisboa, ISSS Departamento Editora.

Payne, Malcolm (2011). Humanistic Social Work, core principles in pratice. Londres: Palgrave Macmillan.

Pessini, L.; Bertachini, L. (2004). Humanização e Cuidados Paliativos. São Paulo: Edições Loyola/Centro Universitário São Camilo, 336 p. 
Rego, Arménio, et al. (2007), Espiritualidade nas organizações, positividade e desempenho, Comportamento Organizacional e Gestão, 2007, Vol. 13, $\mathrm{n}^{\circ}$ 1, 7-36.

Robertis, Cristina de (2005). Metodologia de La Intervención en Trabajo Social. Buenos Aires: Lumen Humanitas.

Rogers, Carl (2011). O poder pessoal. Lisboa: Padrões Culturais Editora.

Silva, Augusto Santos ; Pinto, José Madureira (1999). Metodologia das Ciências Sociais (14 ed.). Porto: Ed. Afrontamento

Strenger, Carlo (2012). O medo da insignificância, como dar sentido às nossas vidas no Séc. XXI. Lisboa: Lua de Papel.

Zohar, Danah; Marshall, Ian (2004). Inteligência Espiritua. Lisboa: Sinais de Fogo. 